\title{
EARLY-CAREER ENGINEERS' PERCEPTIONS OF SUPPORT FOR INNOVATION AT THE WORKPLACE - WHAT SEEMS TO MATTER
}

\author{
Simon, Patrick (1); Björklund, Tua A. (2); Sheppard, Sheri (3) \\ 1: School of Management, Technical University of Munich; 2: Design Factory, School of Engineering, \\ Aalto University; 3: School of Engineering, Stanford University
}

\begin{abstract}
Previous research has shown the importance of contextual factors for increasing employee innovativeness, but to effectively support innovative behavior, we need to also understand what forms of support are perceived as meaningful by the employees themselves. The current study investigated the experiences of 35 early-career engineers in creating, championing and implementing new ideas at the workplace. They reported relatively few instances of support that had been experienced as helpful, and nearly all of these were related to either managerial or co-worker support. This support ranged from encouragement and positive feedback to tangible help in troubleshooting and finding resources, and, in the case of managers, providing sufficient autonomy and responsibility to enable the interviewees to pursue their ideas. Managerial support was most frequently reported by those working in self-described innovative positions, whereas co-worker support was more commonly reported by those working in selfdescribed innovative environments. Formal processes and incentives were less likely to have been perceived as helpful than informal interactions with managers and co-workers.
\end{abstract}

Keywords: Innovation, Support, Project management, Colleagues, Training

\section{Contact:}

Björklund, Tua A.

Aalto University

Design Factory

Finland

tua.bjorklund@aalto.fi

Cite this article: Simon, P., Björklund, T.A., Sheppard, S. (2019) 'Early-Career Engineers' Perceptions of Support for Innovation at the Workplace - What Seems to Matter', in Proceedings of the 22nd International Conference on Engineering Design (ICED19), Delft, The Netherlands, 5-8 August 2019. DOI:10.1017/dsi.2019.181 


\section{INTRODUCTION}

Innovations can create important competitive advantages for companies (Woodman et al., 1993; Yuan and Woodman, 2010). Organizations need to create new products and services, while simultaneously becoming more effective and efficient through process innovations (Tierney et al., 1999; Shalley et $a l ., 2004)$. Efforts to create innovations go hand in hand with design activities, which focus on creating new solutions, transforming existing situations into preferred ones (Simon, 1969). However, managing innovations and innovativeness, with the inherent uncertainty (Lenfle and Loch, 2010; Collyer and Warren, 2009) and changing needs (Kim and Wilemon, 2002; Koen et al., 2001) that goes along with it, can stand in stark contrast to many traditional organizational processes.

Previous research has identified a number of personal factors influencing employee innovativeness, such as motivation, attitudes, and previous knowledge (Zhou and Shalley, 2003). However, contextual factors also play a key role (Madjar et al., 2002). Many researchers view creative ideas as not being generated in an act of isolation, but instead being created through social, interpersonal interaction and communication (e.g. Kanter et al., 1988; Perry-Smith and Shalley, 2003). Furthermore, innovativeness entails not only generating new ideas (i.e. creativity), but advancing and implementing these ideas into practice (Amabile, 1988). Advancing the newly created ideas in organizations is distributed between people (Björklund et al., 2013). Friends, sponsors and backers can play an important role in promoting ideas (Kanter et al., 1988; Dougherty and Heller, 1994). At the same time, innovation challenges the status quo and therefore can violate people's comfort zone and existing framework of thoughts and actions, so resistance to such actions can also be expected within a work community (Kanter et al., 1988; Dougherty and Heller, 1994; Janssen, 2003).

Looking at the social context of innovation, previous studies suggest three key building blocks influencing innovativeness: the organizational culture, leadership, and co-workers at a workplace. The organizational culture should be supportive of an active approach to work (Frese et al., 1996) and offer psychological safety (Edmondson, 1999). For example, having a climate of trust and support has been linked to successful implementation of Total Quality Management approaches (Emery et al., 1996). Not only are these types of cultures conductive of creating innovations, the absence of such a climate can lessen or even negate positive effects of process innovations on company performance (Baer and Frese, 2003).

Leadership plays a crucial role in establishing and manifesting organizational cultures conductive of innovation (Mumford et al., 2002). Communicating expectations and modeling desired behavior, managers help to set the bar for workplace practices (Mumford et al., 2002) A valuable relationship between a supervisor and an employee is considered to result in higher work engagement and thus in greater individual creativity (Scott and Bruce, 1994). Non-controlling and transformational leadership styles have also been connected to employee innovativeness (Oldham and Cummings, 1996; Gong et al., 2009; Wang and Rode, 2010). The support of managers may be particularly relevant for new and early-career employees. For example, Simonton (1983) found that it can be helpful for younger employees to work closely together with mature managers to help transform generated ideas into innovations.

In addition to managers, one's colleagues can also help both to increase domain-relevant knowledge needed for innovations (Perry-Smith and Shalley, 2003) and provide complementary expertise required for interdisciplinary innovations (Kanter et al., 1988). How supportive co-workers are contributes towards psychological safety and whether employees feel comfortable taking the interpersonal risk of voicing new ideas (Edmondson 1991). Bringing up a new idea in front of a coworker can be intimidating, and social distance can hinder - and friendships facilitate - voicing ideas at the workplace (Albrecht and Hall, 1991).

However, studies on support for innovativeness from the perspectives of those engaging in the innovation efforts remain rare. Similar to Fila and Hess (2018) examining different ways engineers understood and experienced innovation, and Daly and colleagues (2012) investigating how professionals connect their perceptions of design to their actions, the current study aims to illuminate how engineers themselves perceive innovativeness and support for it at their workplace. We focus on early-career engineers, as having entered their jobs within only a year or two, they carry perhaps less preconceived notions regarding their industry and organization. These new employees can have a fresh perspective to the operations of the organization, yet little experience in navigating the workplace in general. We thus hypothesize such early experiences to be fertile ground for investigating support for 
innovation efforts as efforts have not been routinized yet, and may thus be easier to articulate. Furthermore, first experiences may encourage or discourage disproportionately subsequent efforts for innovation. For example, Detert and Edmondson (2011) offer anecdotal evidence of the long-carrying effects of first experineces in voicing out ideas during one's career. Indeed, the professional pathways of engineering graduates and the preparations needed for entering and remaining in engineering practice have attracted growing interest (e.g. Brunhaver et al., 2018; Sheppard et al., 2014). Our own research has shown that early-career engineers do indeed engage in innovation efforts, and the social nature of advancing improvement ideas plays a key role in these early experiences (Klenk et al., 2018). In the current study, we extend this research by investigating the types of support that earlycareer engineers themselves perceive meaningful when engaging in innovation efforts - what matters in their eyes. Doing so, we hope to contribute towards understanding what types of support strategies are needed for cultivating innovation at the workplace.

\section{METHODS}

In order to investigate what type of support do early-career engineers perceive for innovation at the workplace, the study adopted a qualitative research approach based on analyzing 35 interviews. The sample was drawn from a larger research study, Engineering Majors Survey (DEL, n.d.), tracking engineers from college to the workplace. Amongst the 27 participating universities, four universities were selected for the sample of this paper based on the size of the subsample of respondents that reported having graduated and started in a full-time job at least six months before the interviews. Interview requests were sent to a portion of this subsample (targeting variety in majors and gender), and 35 engineers agreed to take part in the study.

\subsection{Participants}

The 35 interviewees represented a variety of engineering majors, such as mechanical engineering, civil engineering, biomedical engineering and computer science. A bit over a third of the interviewees were women, and most interviewees were in their early to mid-twenties. They worked in a range of positions, from product development and testing to consulting and sales. Most interviewees worked in large technology companies or consultancies. Pseudonyms were assigned to the interviewees based on the college they had graduated from: ECU1-10 for an East Coast university, MWU1-11 for a Mid-West university, SWU1-7 for a South-West university and WCU1-7 for a West Coast University.

\subsection{Data collection}

In the beginning of the interview, the participants were asked whether they would describe a) their position and b) their work environment as innovative. Aligned with Kvale (1983, p.174), no definition of innovativeness was provided, "to gather descriptions of the life-world of the interviewee with respect to interpretation of the meaning of the described phenomena". If a participant asked for a definition or description, the researchers responded being interested in the participants' definition or concept. The remaining interview was built around a critical incident approach (Cope \& Watts, 2000; Flanagan, 1954), which made it possible to explore participantselected meaningful events in an interviewee's experience in engaging in innovative work. Again, no definition of innovation was provided by the researchers, rather we were interested in what the interviewees themselves equated with "creating, championing or implementing new ideas" (building on top of the Engineering Majors Survey, DEL n.d.). The examples brought up by the participants ranged from self-initiated improvement suggestions to being assigned into teams working on solutions, and included hardware, software and operations development. We refer to these experiences as innovation efforts, as they may or may not have resulted in new, successfully implemented solutions, and most were new-to-organization rather than new-to-field solutions. This can be compared to Farr and Ford's (1990) definition of innovative work behavior as an individual's behavior towards the initiation and application of new and useful ideas, processes, products or procedures. 
The interviews were conducted through Skype or - if possible - in person. Depending on each participant's availability, the interviews varied in duration from 25 to 80 minutes, with the majority lasting between 30 and 40 minutes. The interviews were audio-recoded and transcribed for analysis.

\subsection{Data analysis}

In coding the interviews, we started by classifying the participants responses to whether they perceived their position and work environment as innovative into four categories, based on the direction and strength of their sel-evalutation: 'Yes', 'Yes, somewhat', 'Not really' and 'No'. To assess the connection between the perceived innovativeness of positions and work environments, this was transformed into an ordinal scale of 1 to 4, and a non-parametric Spearman Rank correlation analysis was calculated.

In the second step of coding, all explicit references for support that had been helpful for innovativeness were coded in the interviews. This means that only those instances of received support were coded that the interviewees themselves reported having been meaningful or helpful to their efforts. This resulted in 138 instances of recognized support (or lack thereof). These were grouped together in a data-driven (bottom up) manner based on thematic similarity into three larger groups of support from managers, support from co-workers, and support from the organizational practices or structures, and categorized according to the described type and strength of support received.

Finally, the type and amount of support reported were compared across interviewees according to the perceived innovativeness of their position and work environment.

\section{RESULTS}

\subsection{Perceived innovativeness of the job}

Based on responses to the direct questions of whether interviewees perceived their position and work environment as innovative, 16 interviewees described being in self-described innovative positions in innovative work environments, six in non-innovative positions within innovative work environments, another six in innovative positions within non-innovative work environments, and finally, a total of seven interviewees in self-described non-innovative positions in non-innovative work environments (see Table 1). The perceived innovativeness of the work position and work environment were positively correlated $(\mathrm{rs}=.544, \mathrm{p}<.001)$.

Table 1. Participants' self-evaluations of the innovativeness of their job

\begin{tabular}{|l|c|c|r|}
\hline $\begin{array}{l}\text { Perceived } \\
\text { innovativeness }\end{array}$ & $\begin{array}{c}\text { Innovative work } \\
\text { environment }\end{array}$ & $\begin{array}{c}\text { Non-innovative work } \\
\text { environment }\end{array}$ & $\begin{array}{r}\text { Total } \\
\text { amount }\end{array}$ \\
\hline $\begin{array}{l}\text { Innovative } \\
\text { position }\end{array}$ & $\begin{array}{c}\text { S3, S4, S6, E3, E6, E7, E8, } \\
\text { E9, E10, W1, W2, W3, } \\
\text { W4, M5, M6, M10 }\end{array}$ & S5, E4, E5, M2, M3, M9 & 22 \\
\hline $\begin{array}{l}\text { Non-innovative } \\
\text { position }\end{array}$ & S2, S7, W5, M1, M7, M8 & $\begin{array}{c}\text { S1, E1, E2, W6, W7, M4, } \\
\text { M11 }\end{array}$ & 13 \\
\hline Total amount & 22 & 13 & 35 \\
\hline
\end{tabular}

\subsection{Perceived managerial support for innovativeness}

Over three fourths of the interviewees mentioned different forms of managerial support or a lack thereof contributing towards their ability to innovate. Twenty-four interviewees reported managerial support 51 times, and eight interviewees reported 16 instances of lacking sufficient managerial support.

The "mildest" form of reported support was managers being open and receptive towards ideas suggested by the interviewees. For example, SWU6 described having "never felt, when proposing an opportunity, like that, like I was going to get shut down". Positive feedback from one's direct supervisor (often the first person an interviewee would present a new solution to) was seen as important. For example, WCU4 reported that the supervisor saying "That was great! You did a great job!" was so influential that "that's all I need to carry me through for the next, like, month- 
and-a-half". A few interviewees also reported support from higher level managers, such as ECU8, who described a situation where the CEO of the company recognized some innovative output by saying "I'm really proud of you. Like, thank you so much for all of your hard work! It's really paying off", which for ECU 8 was a "highlight, because if I know I'm doing a good job, that feels awesome, but then when somebody else says, 'You're doing a good job' that feels ten times better. And then when that person is the CEO of your company, that feels just like, ah, it was incredible!". Managers could also actively encourage innovation efforts, asking the interviewees to "make sure to voice your opinion" (ECU7) and any improvement suggestions they might have. For example, ECU4 reported being told in the very beginning that "We're going to teach you to do things the right way the first time. And if there's a better way it can be done, let us know [...] That's like one of the priorities in having you here". Mangers expressing confidence in the interviewee's ability was also perceived as supportive for innovativeness. In total, the support of receptive and encouraging managers was mentioned 13 times.

Moreover, the interviewees described 16 instances where their managers provided direct help and and supported them in creating and pursuing new ideas. This support could, for example, be assisting in finding internal experts, as well as lending their own expertise. For example, WCU1 described his supervisor helping with design choices: "Sometimes, I do get stuck and I think, 'Oh, I don't know how I would attach this. Would I use screws? Would I use clips?' And he 'll help me out". Another means of support offered by the mangers was securing resources and tools for the interviewees to utilize. For example, MWU5's supervisor allowed them to "use any tool we need". Managers could also help spread the improvements created by their employees: "So, my manager was really, like, I guess, prideful about my creation, so he's the one that shared that this tool was available and where to find it." (ECU3).

Providing autonomy and responsibility to the interviewees was the most frequent form of managerial support for innovativeness reported by the interviewees, with a total of 19 mentions. One form of such support was granting procedural autonomy, meaning that employees have leeway in which processes and tools they use to achieve a goal or complete a task: "we're afforded a lot of flexibility to do things in whatever manner it is that we choose" (SWU7). ECU10 mentioned that "day-to-day guidance on how to do stuff is left up to me". However, this was combined with managerial support should problems arise, with for example WCU1 characterizing his instructions as "Figure it out. If it works, awesome. If it doesn't work, we'll work together to find a way to make it work." Multiple interviewees also reported that having a broader and larger role assigned to them gave them the chance to act innovative. For example, SWU1 "was given responsibility to take care of basically all of [product line] products" and described that this responsibility enabled to making significant changes to existing procedures, which "sped up the process".

Noteworthy is that eight interviewees also reported a total of 16 times a lack of managerial support as having hindered their ability to engage in innovation efforts. (Three interviewees reported only such negative instances of lacking managerial support, whereas five interviewees reported both negative and positive instances.) Often, the issue lied in an unreceptive supervisor: for example, ECU5 described that "when I tried to bring the idea of having a designer up, and the kind of resistance and hesitation that I was met with", and SWU2 described their idea being "not received as well as I would have expected" which could be an "issue with my communication". Layers of hierarchy could also make it difficult to proceed, and having a tight scope could discourage innovativeness. For example, ECU 5 described that "they never seem to allow you time to be able to work on ideas", and MWU1 added that working on client projects, "if it's outside of the scope, then we're not getting paid for it".

As shown in Table 2, support was more frequently reported by those in self-described innovative positions than non-innovative ones, although those in innovative work environments also reported many instances of managerial support. The average of just 0.3 instances among those in noninnovative environments and positions stands-out. 
Table 2. Participants' perceptions of managers' support for innovativeness at their job

\begin{tabular}{|c|c|c|}
\hline \begin{tabular}{|l} 
Perceived \\
innovativeness
\end{tabular} & Innovative work environment & Non-innovative work environment \\
\hline Innovative position & $\begin{array}{l}\text { average } 2.1 \text { instances of managerial } \\
\text { support per interview reported: } \\
\text { 11x receptive \& encouraging; } \\
\text { 8x supporting \& helping; } \\
\text { 12x autonomy \& responsibility; } \\
\text { 2x providing a guiding vision } \\
\text { (4x lack of receptiveness) }\end{array}$ & $\begin{array}{l}\text { average } 1.8 \text { instances of managerial } \\
\text { support per interview reported: } \\
\text { 1x receptive \& encouraging; } \\
\text { 3x supporting \& helping } \\
\text { 6x autonomy \& responsibility; } \\
\text { 1x providing a guiding vision } \\
\text { (4x lack of receptiveness; } \\
\text { 4x lack of autonomy) }\end{array}$ \\
\hline $\begin{array}{l}\text { Non-innovative } \\
\text { position }\end{array}$ & $\begin{array}{l}\text { average } 1.3 \text { instances of managerial } \\
\text { support per interview reported: } \\
\text { 1x receptive \& encouraging; } \\
\text { 5x supporting \& helping; } \\
\text { 3x autonomy \& responsibility } \\
\text { (2x lack of receptiveness; } \\
\text { 1x lack of autonomy) }\end{array}$ & $\begin{array}{l}\text { average } 0.3 \text { instances of managerial } \\
\text { support per interview reported: } \\
1 \mathrm{x} \text { supporting \& helping } \\
1 \mathrm{x} \text { autonomy \& responsibility } \\
\text { (1x lack of autonomy) }\end{array}$ \\
\hline
\end{tabular}

\subsection{Perceived co-worker support for innovativeness}

Eighteen out of 35 interviewees brought up different degrees of co-worker support for innovativeness at their job, with a total 35 positive mentions and 2 negative instances.

Again, the "mildest" form of perceived support was co-workers being open and receptive towards ideas suggested by the interviewees. For example, SWU5 reported that due to receptive colleagues within the work environment, "there's never been an issue with feeling insecure of proposing a new idea", and SWU4 and SWU6 described being able to "bounce ideas off' colleagues. A further step in increasing perceived support was receiving positive feedback and encouragement from colleagues. ECU8 for instance described a co-worker that praised their idea, for example by stating "Wow, that's really cool! Let me use that". Co-workers could also help the interviewees feel like they had the mandate to pursue innovative ideas, for example SWU5's co-workers requesting them "to think outside of the box". Receptive and encouraging co-workers were brought up as having supported innovativeness a total of 11 times in the interviews. There were also two interviewees who noted the lack of such receptiveness at their job: MWU9 reported that it inhibited creativity when co-workers were "not on your side", and MWU10 felt some colleagues were actively "trying to block innovation". Co-workers were also described 19 times as having directly helped or otherwise supported the interviewees in their innovation efforts. Colleagues were seen as valuable sources of technical knowledge in particular, and it was seen as important to be able to ask questions from colleagues. As ECU7 argued, "if I don't know the right answer, then maybe my co-worker does". MWU6 described their innovative environment as being one where everyone was "feeling free to reach out to anybody that has any sort of experience". Helping could also be adopting improvement suggestions made by the interviewees, or even, in the case of ECU8, helping to spread solutions developed by the interviewees onwards by recommending others to use them as well. "And that feels awesome! That feels fantastic, because it's something that other people are going to benefit from and, also, I'm getting credit for it." (ECU8). On the other hand, the same interviewee also considered it helpful when colleagues pointed out flaws in bad ideas: "they'll explain to me, '[...] we can't do it that way because of this" (ECU8).

Finally, three interviewees reported that organized brainstorming events amongst colleagues had been helpful, and one interviewee (MWU5) described an informal book club amongst colleagues to review "very, very technical subjects" had been helpful to gain the requisite knowledge for innovativeness.

As shown in Table 3, those in self-described innovative positions in innovative environments described the most positive instances, and co-worker support was more commonly reported by those in self- described innovative work environments than those in innovative positions but non-innovative work environments. 
Table 3. Participants' perceptions of co-workers' support for innovativeness at their job

\begin{tabular}{|c|c|c|}
\hline $\begin{array}{l}\text { Perceived } \\
\text { innovativeness }\end{array}$ & Innovative work environment & Non-innovative work environment \\
\hline Innovative position & $\begin{array}{l}\text { average } 1.6 \text { instances of co-worker } \\
\text { support per interview reported: } \\
8 x \text { receptive \& encouraging; } \\
\text { 14x supporting \& helping; } \\
\text { 4x organized collaboration } \\
\text { (1x lack of receptiveness) }\end{array}$ & $\begin{array}{l}\text { average } 0.5 \text { instances of co-worker } \\
\text { support per interview reported: } \\
\text { 2x receptive \& encouraging; } \\
\text { 1x supporting \& helping } \\
\text { (1x lack of receptiveness) }\end{array}$ \\
\hline $\begin{array}{l}\text { Non-innovative } \\
\text { position }\end{array}$ & $\begin{array}{l}\text { average } 1.0 \text { instances of co-worker } \\
\text { support per interview reported: } \\
\text { 1x receptive \& encouraging; } \\
\text { 4x supporting \& helping; } \\
\text { 1x organized collaboration }\end{array}$ & $\begin{array}{l}\text { No instances of co-worker support } \\
\text { described. }\end{array}$ \\
\hline
\end{tabular}

\subsection{Perceived organizational support for innovativeness}

Seventeen interviewees mentioned organizational support for innovativeness 22 times, mostly in work environments that were perceived as innovative. Seven instances of formal improvement processes and programs were mentioned as having supported innovation efforts. For example, ECU10 described a "formal process for a critique", which "formalizes the process of how can we get better". SWU6's employer set up quarterly goals and encouraged employees to provide ideas and improvement suggestions related to these goals. Formalized incentives were also mentioned seven times, such as monetary rewards in the form of gift cards and cash bonuses. ECU4 explained "a cash gift card is given out for when you kind of go above and beyond by innovating or improving a process on a substantial level". Non-monetary incentives included employee of the month recognition for improvement activities and opportunities to present work to the leadership team.

Finally, seven instances of formal training and one informal training arrangement were mentioned as having supported innovation efforts. For example, as ECU7 explained that "if you want a certificate and it could potentially be helpful for a project, then they're going to encourage you to do it and provide the funding for it", because "any additional knowledge is always great, especially if it's project-based or can help a project out".

Interestingly, those in self-assessed non-innovative positions but innovative environments were more likely to include examples of organizational support in their experience descriptions (nine instances, averaging at 1.5 per interview) than those in self-assessed innovative positions (an average of 0.5-0.6 instances per interview). Those in non-innovative positions in non-innovative environments mentioned only one training opportunity (averaging at 0.1 instances per interview).

\section{DISCUSSION}

Examining the innovation experiences of 35 early-career engineers, instances where they explicitly attributed support having helped in their efforts were relatively rare. The 138 described instances (averaging at just below four instances per interview) were largely interpersonal, the interviewees describing the receptiveness and help of their managers and co-workers, and, less frequently, formal procedures, incentives and access to training. Overall, most instances of support were described by those interviewees who perceived both their position and work environment as innovative. Conversely, those who perceived neither their work environments nor position as innovative described very little support of any kind (be it co-worker, managerial, or organizational). As the current study is cross-sectional, we cannot assess causality based on the current results, but we suspect that the available support perceived by the interviewees influenced their assessments of job innovativeness. Managerial support was described more often in the context of innovative positions, whereas coworker support and formal incentives, procedures and training were more connected to innovative work environments.

Managerial support was the most commonly recognized form of support that had been seen to help innovation efforts. The managers' initial reactions to ideas carried much weight: positive feedback 
could elate the interviewed engineers, offering validation and creating memorable top moments for them. Managers also provided tangible help both personally, lending their expertise and helping to spread new solutions in the organization, as well as by connecting the interviewees to others in the organization. Indeed, in addition to guiding work within projects, leading innovation efforts often requires managers to act as liaisons within the organization as well as with external stakeholders (Elkins and Keller, 2003). It is important to note that a lack of managerial receptiveness for improvement suggestions was the single most common perceived hindrance to innovation, reported by a fifth of the interviewees.

In addition to supporting specific initiatives, managers were perceived as playing an important role in creating fruitful conditions for innovative work in the first place. They sometimes requested new ideas and solutions directly, but more often the autonomy and responsibility they provided to the interviewees were seen as important enablers, creating the needed flexibility and scope to pursue ideas. Previous research has connected both felt responsibility and top management openness to employees initiating change at the workplace (Morrison and Phelps, 1999). The current study suggests that even if the scope and goals of a role are set, offering procedural autonomy in how tasks are accomplished can help to encourage innovation. For early-career engineers, the attitudes and practices of immediate supervisors can carry more weight than those of the organization in general - managerial support was most commonly reported by those in self-described innovative positions.

While overall similar levels of encouragement and help were reported from managers and colleagues in the data set, co-worker support was concentrated in the experiences of fewer interviewees. Approximately half of the interviewees had experienced co-worker support to help them in their innovation efforts, most of them working in what they described as innovative work environments. If co-workers were mentioned, it was nearly always in a positive light. Like with managers, the interviewees reported both more passive support (being receptive and acknowledging good results) and active support (encouraging and helping the interviewees) from their colleagues. Co-workers seemed to be particularly important for helping with technical issues and answering questions arising with new ideas and developing them further, extending the expertise available for the interviewees (Perry-Smith and Shalley, 2003).

Formal support in the shape of organized brainstorming sessions, incentives for innovation efforts and training opportunities were also acknowledged. In addition to communicating norms of the desirability of innovation and increasing technical knowledge, these seemed to include an important networking element. Many of these meetings brought together people from different departments and units, providing the interviewees with contact to whom they could then reach out to when encountering problems or looking for feedback on their ideas.

Taken together, the current study highlights the social element of innovation efforts, both in terms of providing access to sufficient technical knowledge in the network of people within an organization, and in encouraging employees to engage in such efforts in the first place. Although more research is needed on how these relationships unfold as well as examining the connection between subjective evaluations and characteristics of the work, the current study offers preliminary practical implications. First and foremost, particularly immediate managers should be receptive regarding improvement suggestions and quick to provide acknowledgement, as positive feedback from managers carried much weight for the early-career engineers and could energize them. Providing at least procedural autonomy where possible and offering one's own expertise to help troubleshoot, as well as connecting subordinate to colleagues within the organization, were also appreciated. Similarly, co-workers can encourage creating and pursuing creative ideas, and arranging time and opportunities to find the needed connections across departments and functions can help to lessen the dependency of an earlycareer engineer on their immediate supervisor and team alone for support. As the current study focused on those forms of support that the interviewees recognized themselves and found meaningful, these may be connected to subsequent motivation to engage in innovation efforts, but more empirical research is needed to verify this. Furthermore, it would be interesting to compare these acts of support perceived as helpful to the wider variety of interactions engineers engage with their managers and coworkers in their innovation efforts. Are there patterns of interaction that repeat in successful and unsuccessful efforts that the engineers themselves are not aware of? Going forward, these questions seem important to address in order to improve strategies to support innovation. In light of the current study, informal interactions with management and colleagues seem to be highly meaningful, above 
and beyond those of formal mechanisms and policies, in the day-to-day efforts of creating innovations. A number of small acts can create a meaningful difference when it comes to perceived support.

\section{REFERENCES}

Amabile, T.M. (1988), "A model of creativity and innovation in organizations", Research in Organizational Behavior, Vol. 10 No. 1, pp. 123-167.

Baer, M. and Frese, M. (2003), "Innovation is not enough: climates for initiative and psychological safety, process innovations, and firm performance", Journal of Organizational Behavior, Vol. 24 No. 1, pp. 45-68.

Björklund, T.A., Bhatli, D. and Laakso, M. (2013), "Understanding idea advancement efforts in innovation through proactive behavior", Journal of Research in Marketing and Entrepreneurship, Vol. 15 No. 2, pp. $124-142$.

Brunhaver, S.R., Korte, R.F., Barley, S.R. and Sheppard, S.D. (2018), "Bridging the gaps between engineering education and practice", In: R. Freedman and H. Salzman, (Ed.), U.S. Engineering in a Global Economy, National Bureau of Economic Research.

Collyer, S. and Warren, C. (2009), "Project management approaches for dynamic environments", International Journal of Project Management, Vol. 27 No. 4, pp. 355-264.

Cope, J. and Watts, G. (2000), "Learning by doing - an exploration of critical incidents and reflection in entrepreneurial learning", International Journal of Entrepreneurial Behaviour \& Research, Vol. 6 No. 3, pp. 104-124.

Daly, S.R., Adams, R.S. and Bodner, G.M. (2012), "What does it mean to design? A qualitative investigation of design professionals' experiences”, Journal of Engineering Education, Vol. 101 No. 2, pp. 187-219.

DEL,(n.d), Engineering Majors Survey. https://del.stanford.edu/research-projects/engineering-majors-survey

Detert, J.R. and Edmondson, A.C. (2011), "Implicit voice theories: Taken-for-granted rules of self-censorship at work", Academy of Management Journal, Vol. 54, pp. 461-488.

Dougherty, D. and Heller, T. (1994), "The illegitimacy of successful product innovation in established firms", Organization Science, Vol. 5, pp. 200-218.

Edmondson, A. (1999), "Psychological safety and learning behavior in work teams", Administrative Science Quarterly, Vol. 44, pp. 350-383.

Elkins, T. and Keller, R.T. (2003), "Leadership in research and development organizations: A literature review and conceptual framework", Leadership, Vol. 14, pp. 587-606.

Emery, C.R., Summers, T.P. and Surak, J.G. (1996), "The role of organizational climate in the implementation of total quality management", Journal of Managerial Issues, Vol. 8, pp. 484-496.

Farr, J. and Ford, C. (1990), "Individual Innovation”, In: M. West and J. Farr, (Ed.), Managing Innovation, Sage, London.

Fila, N.D. and Hess, J.L. (2018), “Critical incidents in engineering students' development of more comprehensive ways of experiencing innovation”, 2018 ASEE Annual Conference and Exposition, Salt Lake City, Utah, American Society for Engineering Education.

Flanagan, J.C. (1954), “Critical incident technique”, Psychological Bulletin, Vol. 51 No. 4, pp. 327-358.

Frese, M., Kring, W., Soose, A. and Zemper, J. (1996), "Personal initiative at work: differences between East and West Germany", Academy of Management Journal, Vol. 39, pp. 37-63.

Gong, Y., Huang, J.C. and Farh, J.L. (2009), "Employee learning orientation, transformational leadership, and employee creativity: The mediating role of employee creative self-efficacy", Academy of Management Journal, Vol. 52 No. 4, pp. 765-778.

Janssen, O. (2003), "Innovative behaviour and job involvement at the price of conflict and less satisfactory relations with co-workers", Journal of Occupational and Organizational Psychology, Vol. 76, pp. 347-364.

Kanter, R., Staw, B.M. and Cummings, L.L. (1988), "When a thousand flowers bloom: Structural, collective, and social conditions for innovation in organizations, Research in Organizational Behavior, JAI Press, Greenwich, CT, Vol. 10, pp. 169-211.

Kim, J. and Wilemon, D. (2002), "Strategic issues in managing innovation's fuzzy front-end", European Journal of Innovation Management, Vol. 5 No. 1, pp. 27-30.

Klenk, M., Björklund, T., Gilmartin, S. and Sheppard, S.D. (2018), "Early-career Engineers at the Workplace: Meaningful Highs, Lows and Innovative Work Efforts", American Society for Engineering Education (ASEE) Annual Conference 2018, Salt Lake City.

Koen, P., Ajamin, G., Burkart, R., Clamen, A., Davidson, J., D'Amore, R., Elkins, C., Herald, K., Incorvia, M., Johnson, A., Karol, R., Seibert, R., Slavejkov, A. and Wagner, K. (2001), "Providing clarity and common language to the fuzzy front end", Research Technology Management, Vol. 44 No. 2, pp. 46-55.

Kvale, S. (1983), "The quantification of knowledge in education: On resistance toward qualitative evaluation and research, The sociogenesis of language and human conduct, Springer, Boston, MA, pp. 433-447.

Lenfle, S. and Loch, C. (2010), "Lost roots: how project management came to emphasize control over flexibility and novelty", California Management Review, Vol. 53 No. 1, pp. 1-24. 
Madjar, N., Oldham, G.R. and Pratt, M.G. (2002), "There's no place like home? The contributions of work and nonwork creativity support to employees' creative performance", Academy of Management Journal, Vol. 45 No. 4, pp. 757-767.

Morrison, E.W. and Phelps, C. (1999), "Taking charge: Extra-role efforts to initiate workplace change", Academy of Management Journal, Vol. 42 No. 4, pp. 403-419.

Mumford, M.D., Scott, G.M., Gaddis, B. and Strange, J.M. (2002), "Leading creative people: Orchestrating expertise and relationships", The Leadership Quarterly, Vol. 13 No. 6, pp. 705-750.

Oldham, G.R. and Cummings, A. (1996), "Employee creativity: Personal and contextual factors at work", Academy of Management Journal, Vol. 39 No. 3, pp. 607-634.

Perry-Smith, J.E. and Shalley, C.E. (2003), "The social side of creativity: A static and dynamic social network perspective", Academy of Management Review, Vol. 28 No. 1, pp. 89-106.

Scott, S.G. and Bruce, R.A. (1994), "Determinants of innovative behavior: A path model of individual innovation in the workplace”, Academy of Management Journal, Vol. 37 No. 3, pp. 580-607.

Shalley, C.E., Zhou, J. and Oldham, G.R. (2004), "The effects of personal and contextual characteristics on creativity: Where should we go from here?”, Journal of Management, Vol. 30 No. 6, pp. 933-958.

Sheppard, S.D., Antonio, A.L., Brunhaver, S.R. and Gilmartin, S.K. (2014), "Studying the career pathways of engineers: An illustration with two datasets", In: A. Johri and B. M. Olds, (Ed.), Cambridge Handbook of Engineering Education Research, Cambridge University Press, New York, NY, pp. 283-309.

Simon, H.A. (1969), The sciences of the artificial, MIT Press, Cambridge, MA.

Tierney, P., Farmer, S.M. and Graen, G.B. (1999), “An examination of leadership and employee creativity: The relevance of traits and relationships”, Personnel Psychology, Vol. 52 No. 3, pp. 591-620.

Wang, P. and Rode, J.C. (2010), "Transformational leadership and follower creativity: the moderating effects of identification with leader and organizational climate", Human Relations, Vol. 63 No. 8, pp. 1105-1128.

Woodman, R.W., Sawyer, J.E. and Griffin, R.W. (1993), "Toward a theory of organizational creativity", Academy of Management Review, Vol. 18 No. 2, pp. 293-321.

Yuan, F. and Woodman, R.W. (2010), "Innovative behavior in the workplace: The role of performance and image outcome expectations", Academy of Management Journal, Vol. 53 No. 2, pp. 323-342.

\section{ACKNOWLEDGMENTS}

The larger Engineering Majors Survey research study has been supported by the National Science Foundation (grant number 1636442) as well as the National Center for Engineering Pathways to Innovation (Epicenter), a center funded by the National Science Foundation (grant number DUE1125457), directed by Stanford University and VentureWell. 